\title{
Atividades do Senado Federal brasileiro na área de saúde pública, 1995 e 1996
}

\author{
Luiz Carlos Romero, ${ }^{1}$ Heloísa Tartarotti Camargo, ${ }^{1}$ Edilenice Lima \\ Passos, ${ }^{1}$ Berenice de Sousa Otero, ${ }^{1}$ Heloísa Inês Magalhães, ${ }^{1}$ \\ Antônio Pereira de Paula ${ }^{1}$ e Sérgio F. P. O. Penna ${ }^{1}$
}

RESUMO O presente estudo buscou identificar e descrever as ações dos senadores brasileiros, na área de saúde pública, no perído de 1995 a 1996. Pretendeu-se também identificar a influência da profissão, região de origem e partido político sobre a atuação dos senadores. As ações foram divididas em três grupos: legislativas (proposição e apreciação de projetos de lei, pareceres e requerimentos), fiscalizadoras (requerimentos de informação ao Executivo e implementação de comissões parlamentares de inquérito e especiais) e parlamentares (discursos). O levantamento dos dados foi realizado em duas bases de dados mantidas pelo Senado Federal: MATE e DISC. Dos 89 parlamentares que exerceram mandato no período do estudo, 76 se envolveram com matérias de saúde. Foram estudadas 667 ações. Predominaram os discursos (43\% das ações), em sua maioria respondendo a notícias veiculadas pelos meios de comunicação. Do total de ações, $60 \%$ envolveram politicas públicas (30\%), drogas (9\%), regulamentação das profissões de saúde (8\%), controle de doenças (7\%) e saúde do trabalhador (6\%). A atividade fiscalizadora foi limitada (5\% das ações foram requerimentos de informação). Em relação ao perfil dos senadores, predominaram os médicos, professores e jornalistas. Os parlamentares das Regiões Norte e Nordeste realizaram $62 \%$ de todas as ações e atuaram em relação a quase todos os temas. Os senadores de orientação liberal e de direita responderam por $43 \%$ de todas as ações; contudo, os de orientação socialista e trabalhista apresentaram maior participação proporcional (em termos de senadores envolvidos e de ações realizadas). É interessante notar que os senadores socialistas e trabalhistas não se envolveram com o tema "saúde do trabalhador". A predominância de discursos como ação, a proposição legislativa pontual e descontínua e, especialmente, a incipiente ação fiscalizadora, indicam a necessidade de reformular a sistemática de trabalho no âmbito das comissões técnicas e da consultoria técnica do Senado.

A saúde constitui, conforme a Constituição brasileira de 1988, "direito de todos e dever do Estado" e o desempenho do setor tem merecido acalorados debates no Congresso e na socie-

\footnotetext{
1 Brasil, Consultoria Legislativa do Senado Federal. Correspondência e pedidos de separatas devem ser enviados a Luiz Carlos Romero no seguinte endereço: Consultoria Legislativa, Senado Federal, CEP 70165-900, Brasília, DF, Brasil. Telefone: +55-61-311-3303; fax: +55-61-311-4351; e-mail: romero@senado.gov.br
}

dade. Sucessivas tragédias, como a morte de 63 pacientes em serviços e de hemodiálise em Caruaru (1-3) e de mais de uma centena de idosos internados em casas de saúde no Rio de Janeiro (4-6) ou vários episódios de hipermortalidade de bebês em maternidades de várias cidades (7-10), alertaram, dramaticamente, sobre a falência de um sistema essencial ao bem estar da população. A instituição de uma nova contribuição social sobre movimentações financeiras para financiamento de ações e serviços de saúde, compulsória desde 1997, caracteriza um sistema falido, incapaz de atender aos requisitos básicos da população. Na prática, o Congresso brasileiro tem atuado como fiscalizador prioritariamente por motivações exógenas, de forma pontual e reativa, especialmente quando da ocorrência de fatos como esses, que ganham ampla repercussão nos meios de comunicação.

Basicamente, o poder legislativo deveria cooperar com a sociedade na pro- 
dução e modificação das leis de saúde existentes, na fiscalização das ações do executivo e no controle e liberação de verbas quando da apreciação dos planos plurianuais e dos orçamentos anuais. Com a promulgação da Constituição Federal de 1988, o Senado Federal brasileiro recuperou suas prerrogativas de órgão legislativo e de fiscalização, que demandam um crescente aporte técnico, à semelhança do que ocorre nos parlamentos de maior tradição democrática. Tal aporte técnico está diretamente relacionado com o aumento na complexidade e diversidade dos temas a serem examinados pelos parlamentares.

O desenvolvimento desse tipo de atividade de apoio às decisões do parlamento implica na geração de informação através de estudos e trabalhos de pesquisa e de alterações na sistemática do trabalho legislativo, especialmente no que diz respeito à maior participação nas decisões sobre políticas públicas. A revisão da forma de trabalho do legislativo e a identificação dos entraves e das falhas deverão proporcionar alternativas mais eficientes, tanto para o Congresso quanto para a sociedade.

Considerando as atribuições legislativas e de fiscalização do Senado, o objetivo deste estudo foi caracterizar e descrever a atividade dos senadores na área de saúde pública e identificar variáveis relativas ao perfil dos parlamentares capazes de influir no desempenho dos mesmos, individual e coletivamente. O período considerado para análise foram os anos de 1995 e 1996.

\section{MATERIAIS E MÉTODOS}

\section{Caracterização das ações}

As atividades do Senado, para fins de análise, foram divididas em três grandes categorias: legislativa, fiscalizadora e parlamentar. No intuito de abranger estas três grandes funções, foram considerados cinco grupos de ações: 1) projetos de lei e de decretos legislativos; 2) pareceres; 3) requeri- mentos de informação; 4) discursos, inclusive os apartes; e 5) outras, que compreende as atividades de um parlamentar como debatedor e membro de comissão, assim como as proposições de emenda, apresentações de voto em separado, solicitações de inclusão na ordem do dia, requerimentos de reexame, pedidos de vistas, requerimentos de tramitação conjunta, requerimentos de urgência, pedidos de transcrição e requerimentos para que seja ouvida outra comissão. As ações incluídas nos grupos 1, 2 e 5 caracterizam o processo legislativo; as do grupo 3 tipificam a ação fiscalizadora; e as do grupo 4, a função parlamentar.

Para fins de análise, foram consideradas todas as ações dos senadores que tratassem de matéria de saúde. Em relação à autoria das ações, foi decidido que, na ocorrência de vários autores, todos seriam creditados, razão pela qual uma mesma ação pode aparecer várias vezes, representando as ações individuais dos parlamentares.

É importante observar que cada projeto de lei, peça central no processo legislativo, gera vários pareceres e ações legislativas diversas, por tramitar nas comissões e no plenário, num processo que pode demorar muitos meses ou anos, desde sua apresentação até sua transformação em lei ou sua rejeição. Assim, muitos projetos e comissões iniciados antes de 1995 originaram, no período de estudo (1995-1996), pareceres, requerimentos e demais ações. Para o presente estudo, somente foram computados como tal os projetos de lei e de decretos legislativos apresentados no período em análise. Todas as demais ações, como pareceres e requerimentos, relacionadas a projetos de lei ou de decretos legislativos já em tramitação, foram consideradas no momento de sua ocorrência, independentemente da época em que o projeto (fato gerador) foi apresentado. Dessa forma, os projetos de lei que haviam sido propostos antes de 1995 não foram considerados como ações no presente estudo, mas as ações decorrentes da tramitação desses projetos de lei foram consideradas, quando ocorreram no período de estudo.

\section{Definição dos grandes grupos temáticos}

Com a finalidade de contemplar os assuntos mais importantes, do ponto de vista técnico e conjuntural, e permitir sua pesquisa num banco de dados indexado, como é o caso dos bancos de dados utilizados, os grupos temáticos com que se ocupou o Senado, no período pesquisado, foram identificados a partir do levantamento e análise de todas as ações relacionadas à saúde pública. A identificação dos grupos temáticos foi feita pela pesquisa e análise, nas bases de dados, de todas as ações centradas em matérias de saúde realizadas por um senador, usando-se como argumento de pesquisa o nome do senador e o período. Temas cuja freqüência foi muito baixa (menos de cinco ações) foram agrupados como "outros". Assim, foram considerados todos os temas relacionados à saúde pública, tratados no Senado no período estudado, agrupados com segue:

1) Políticas públicas de saúde: administração e organização do sistema de saúde, incluindo tópicos como políticas governamentais, sistema único de saúde (SUS), financiamento do setor, orçamentos, pessoal, fiscalização e controle físicofinanceiro e situação do setor.

1.1) Regulamentação das profissões na área de saúde. Conceitualmente, este tema faz parte do grupo anterior, mas, devido ao grande número de ações, foi considerado isoladamente para fins de análise.

2) Políticas de saúde pública específicas, que incluem os seguintes itens:

2.1) saúde reprodutiva;

2.2) alimentação e nutrição;

2.3) saúde da criança e do adolescente;

2.4) saúde do idoso;

2.5) controle de doenças;

2.6) saúde do trabalhador;

2.7) transplantes;

2.8) vigilância sanitária.

3) Drogas.

4) Planos e seguros de saúde. 
5) Outros (inclui todos os tópicos não contemplados nos itens acima).

"Drogas" e "planos e seguros de saúde" foram incluídos separadamente pois, embora possam ser considerados como políticas públicas de saúde, envolvem, pela sua natureza, outros setores do governo, além do setor de saúde.

\section{Coleta de dados}

Em relação a cada parlamentar, foram levantados os seguintes dados: formação profissional, região de origem do senador e orientação ideológica do partido de filiação.

A profissão e o partido do senador foram definidos conforme a profissão informada em publicação do Senado (11). Quando havia indicação de mais de uma profissão, considerou-se a primeira. Algumas profissões, como jornalista, professor, empresário, pecuarista e escritor foram, com freqüência, informadas como uma segunda profissão. Em relação ao partido, como alguns senadores mudaram de partido desde a data da publicação do material consultado, ou durante o período do estudo, o critério adotado foi o de considerar o partido ao qual o senador estava filiado no momento da ação considerada, o que é informado pela base de dados.

A caracterização da orientação ideológica dos senadores foi dificultada pela ausência de distinções ideológicas marcantes entre os partidos políticos brasileiros. Assim, o estabelecimento da orientação político-partidária tornouse arbitrário e subjetivo, introduzindo um elemento de crítica aos resultados obtidos. Entretanto, considerando que tal orientação é essencial à análise, definiu-se uma classificação com base na literatura consultada $(12,13)$ e de acordo com os posicionamentos políticos habitualmente adotados pelos partidos (tabela 1).

O levantamento de proposições legislativas que iniciaram sua tramitação e das que tramitavam no Senado Federal nos anos de 1995 e 1996, assim como de todos os discursos e apartes
TABELA 1. Correlação entre orientação ideológico-partidária e partido político de filiação, Brasil

\begin{tabular}{lc}
\hline $\begin{array}{c}\text { Perfil } \\
\text { ideológico-partidário }\end{array}$ & $\begin{array}{c}\text { Partidos políticos } \\
\text { de filiação }\end{array}$ \\
\hline Comunistas & PPS \\
Socialistas e trabalhistas & PDT, PSB, PT \\
Social-democratas & PSDB \\
Centristas & PMDB \\
Liberais e direita clássica & PFL, PL, PP, PPB, \\
& PPR, PTB \\
\hline
\end{tabular}

realizados no mesmo período, foi realizado em duas bases de dados gerenciadas e mantidas pelo Senado Federal: MATE e DISC. A primeira base reúne matérias legislativas em tramitação ou que já tramitaram no Senado Federal, na Câmara dos Deputados e no Congresso Nacional, desde 1973; a segunda arrola referências e resumos dos pronunciamentos proferidos pelos senadores e deputados, com a indicação de aparteantes, desde março de 1973.

Na base de dados MATE, a recuperação das informações pode ser feita usando-se, como argumento de pesquisa, o assunto, o autor, a origem (Congresso Nacional, Senado Federal ou Câmara dos Deputados), as datas, o número da proposição legislativa ou quaisquer outras palavras que constem do documento. O DISC permite a busca por assunto, autor, data, aparteantes ou quaisquer outras palavras que constem do documento. Todos os argumentos de busca podem ser utilizados individualmente ou combinados entre si.

Nesse levantamento, utilizou-se, como argumento de pesquisa, nas duas bases de dados, o nome do senador, combinado com os anos de 1995 e 1996, período abrangido pelo estudo em questão. Para a identificação dos senadores que exerceram o cargo nos anos de 1995 e 1996, utilizou-se, como fonte de pesquisa, o Relatório da Presidência do Senado Federal $(14,15)$ e a lista de presença.

Obteve-se, como resultado, uma lista de 89 senadores, que incluía nomes de suplentes que assumiram o cargo nos anos estudados. Dessa forma, realizamos a verificação completa de toda a lista de documentos do período para cada senador, utilizando o nome do senador combinado com os anos estudados.

\section{Tratamento dos dados}

Em primeiro lugar, buscou-se relacionar os temas tratados com as espécies legislativas (projeto, parecer, requerimento, discurso), isto é, com a forma com que foram tratados.

Para pôr em evidência a possível influência das profissões, da região de origem e da orientação político-ideológica dos parlamentares na sua atuação, adotaram-se os seguintes indicadores:

a) Senadores envolvidos: indicador calculado dividindo-se a proporção de senadores com uma determinada característica (profissão, região de origem, orientação ideológico-partidária) que se envolveram com o tema, em relação ao total de senadores existentes com a mesma característica, pela proporção de senadores com a característica considerada em relação ao total de senadores.

Com esse indicador, buscou-se quantificar o grau de prioridade dado a cada tema pelos vários grupos de senadores, homogêneos quanto a determinadas características, comparativamente aos demais grupos existentes para esta mesma característica. Por exemplo: na análise da influência da característica "profissão", quantificou-se o grau de prioridade dado pelo grupo de senadores médicos aos temas de saúde em comparação com o grau de prioridade dado por grupos de senadores de outras profissões.

Quanto mais próximo de 1, mais parecido é o envolvimento com o tema por parte do grupo considerado com a proporção com que ele se representa no Plenário. O grau de prioridade ou de ausência de prioridade que o grupo considerado confere ao tema é dado pelo grau de afastamento do valor 1 , respectivamente para mais e para menos. Os valores elevados são interpretados como indicativos de que o tema é uma prioridade na agenda do grupo 
considerado, em conseqüência do que seus participantes se envolvem muito com o mesmo. Os valores muito baixos significam que o tema não é prioridade na agenda do grupo, isto é, os senadores desse grupo se envolveram pouco com o tema. O máximo de ausência de prioridade é identificado pelo valor zero do indicador, que ocorre quando os senadores do grupo não se envolvem absolutamente com o tema.

b) Ações realizadas: indicador calculado dividindo-se a proporção de ações, relativas a um tema, realizadas por senadores com uma determinada característica (profissão, região de origem, orientação ideológico-partidária), em relação ao total de ações realizadas, relativas ao tema considerado, pela proporção de senadores com a característica considerada em relação ao total de senadores.

Permite quantificar a intensidade da atuação parlamentar dos diversos grupos sobre um determinado tema, o que é uma outra medida da prioridade conferida ao tema na agenda do grupo considerado. Avalia-se com os mesmos critérios do indicador $a$ e deve ser interpretado comparativamente, pois, supostamente, um tema prioritário na agenda de determinado grupo (indicador $a$ com valor elevado) deverá ter sido objeto de uma intensa atuação parlamentar (elevado número de ações) por parte de representantes desse grupo e, em conseqüência, o indicador $b$ também deverá apresentar valor elevado.

O uso concomitante dos dois indicadores procura reduzir discrepâncias decorrentes de números pequenos de observações em relação a determinados temas ou características dos parlamentares envolvidos.

A referida análise permitiu caracterizar a atuação do Senado em relação à importância, relativa ou conjuntural, conferida aos vários temas tratados no período e, ao mesmo tempo, identificar quais os grupos (regionais, profissionais e partidários) mais atuantes em relação a cada tema. Também permitiu caracterizar essa atuação em relação às espécies legislativas (projetos, discursos, requerimentos, comissões de inquérito etc.) com que esses temas foram tratados.

\section{RESULTADOS}

Dos 89 parlamentares que exerceram mandato no período do estudo, 76 se envolveram com matérias de saúde. Foram estudadas 667 ações versando sobre matérias de saúde (tabela 2).

A análise dos dados revelou que $43 \%$ das ações realizadas foram discursos; $18 \%$ foram pareceres, $7 \%$ foram projetos, $5 \%$ foram requerimentos e $28 \%$ das ações foram enquadradas na categoria "outros".

Em termos de caracterização dos parlamentares mais envolvidos com os temas de saúde, a análise revelou que houve influência da profissão do parlamentar no seu desempenho, predominando a formação médica ou na área social (por exemplo, professores e jornalistas) (tabelas 3-5). Do total de ações realizadas, $18 \%$ foram feitas por médicos.

Os parlamentares das Regiões Norte e Nordeste, regiões menos desenvolvidas, onde os indicadores sanitários são piores $(16,17)$ apresentaram maior participação em número de ações: $62 \%$ das ações relacionadas à matéria foram realizadas por senadores provenientes dessas duas regiões. A distribuição por região foi a seguinte: $33 \%$ das ações foram realizadas por senadores da região Nordeste; 29\%, do Norte;
$16 \%$, do Sudeste; $15 \%$, do CentroOeste; e 7\%, do Sul (tabela 6).

A bancada da Região Norte esteve envolvida em elevada proporção (em geral acima de $40 \%$ a mais do que o percentual com que se representa no Plenário) com a grande maioria dos temas estudados, evidenciando-se o mesmo em relação ao número de ações realizadas.

A bancada do Centro-Oeste foi a segunda em relação ao número de senadores envolvidos e a terceira em número de ações realizadas. Contudo, esta bancada teve pequena participação, tanto em relação ao envolvimento de seus senadores, quanto a ações que realizaram, em relação a temas como "saúde reprodutiva", "saúde da criança", "saúde do trabalhador" e "planos e seguros de saúde" (indicadores a e b menores do que 1).

Os senadores nordestinos, apesar de terem realizado o maior número de ações, envolveram-se, em proporção significativa, com poucos temas ("saúde do trabalhador", "transplantes" e "alimentação e nutrição") (indicadores a e b maiores do que 1 ).

$\mathrm{O}$ envolvimento com alguns poucos temas específicos também foi característico da bancada do Sudeste, enquanto os representantes da Região Sul apresentaram participação signifi-

TABELA 2. Ações realizadas segundo a espécie e os temas, Senado Federal, Brasil, 1995 e 1996

\begin{tabular}{|c|c|c|c|c|c|c|}
\hline \multirow[b]{2}{*}{ Temas } & \multicolumn{6}{|c|}{ Tipo de ação } \\
\hline & Projeto & Parecer & Requerimento & Discurso & Outros & Total \\
\hline Políticas públicas & 8 & 17 & 14 & 116 & 43 & 198 \\
\hline Regulamentação de profissões & & & & & & \\
\hline de saúde & 6 & 16 & 1 & 4 & 28 & 55 \\
\hline Saúde reprodutiva & - & 3 & - & 20 & 10 & 33 \\
\hline Alimentação e nutrição & - & 1 & 3 & 10 & 5 & 19 \\
\hline $\begin{array}{l}\text { Saúde da criança e do } \\
\text { adolescente }\end{array}$ & & & & & & \\
\hline Saúde do idoso & 1 & 2 & 3 & 3 & 11 & 20 \\
\hline Controle de doenças & 2 & 6 & 1 & 35 & 4 & 48 \\
\hline Saúde do trabalhador & 3 & 10 & - & 1 & 24 & 38 \\
\hline Transplantes & 4 & 9 & 1 & 5 & 13 & 32 \\
\hline Vigilância sanitária & 5 & 12 & 1 & 5 & 10 & 33 \\
\hline Drogas & 9 & 23 & 2 & 20 & 7 & 61 \\
\hline Planos e seguros de saúde & 6 & 7 & - & 6 & 2 & 21 \\
\hline Outros temas & 3 & 9 & 2 & 50 & 14 & 78 \\
\hline Total-n (\%) & $47(7)$ & 119(18) & $32(5)$ & $284(43)$ & $185(28)$ & $667(100)$ \\
\hline
\end{tabular}


TABELA 3. Envolvimento dos senadores com temas de saúde pública conforme a profissão, Brasil, 1995 e 1996 a

\begin{tabular}{|c|c|c|c|c|c|c|}
\hline Temas & Médico & Professor & Jornalista & Administrador & Economista & Advogado \\
\hline Regulamentação de profissões de saúde & 2,39 & 1,33 & 0,82 & 0,89 & - & 0,63 \\
\hline Saúde reprodutiva & 3,43 & 3,42 & 1,71 & - & 0,97 & 0,49 \\
\hline Saúde da criança & 2,03 & 2,52 & 2,02 & 2,02 & 1,01 & 0,58 \\
\hline Saúde do idoso & 4,98 & 0,92 & 1,84 & - & 0,92 & 1,06 \\
\hline Controle de doenças & 2,03 & 2,02 & 2,02 & - & 0,50 & 0,72 \\
\hline Vigilância sanitária & 1,49 & 1,11 & 2,22 & - & 1,67 & 1,27 \\
\hline Drogas & 1,60 & 1,19 & 1,11 & 2,38 & 0,79 & 1,13 \\
\hline Planos e seguros de saúde & 2,30 & - & 1,71 & - & 0,97 & 1,46 \\
\hline Outros temas & 2,85 & 1,32 & 1,58 & 0,74 & 0,53 & 0,75 \\
\hline
\end{tabular}

a Valor calculado dividindo-se a proporção de senadores de cada profissão que se envolveram com o tema, em relação ao total de senadores em cada profissão, pela proporção de senadores de cada profissão em relação ao total de senadores. Quanto mais próximo de 1, mais parecido é o envolvimento com o tema por parte do grupo com a proporção com que ele se representa no plenário. $\mathrm{O}$ grau de prioridade ou de ausência de prioridade que o grupo considerado confere ao tema é dado pelo grau de afastamento do valor 1 , respectivamente para mais e para menos.

TABELA 4. Intensidade da atuação dos senadores conforme a profissão, Brasil, 1995 e $1996^{\text {a }}$

\begin{tabular}{|c|c|c|c|c|c|c|}
\hline Temas & Médico & Professor & Jornalista & Administrador & Economista & Advogado \\
\hline Regulamentação das profissões de saúde & 2,45 & 2,83 & 0,81 & 2,03 & - & 0,46 \\
\hline Saúde reprodutiva & 3,16 & 4,04 & 0,67 & - & 2,61 & 0,48 \\
\hline Saúde da criança & 1,45 & 2,87 & 0,72 & 0,72 & 2,51 & 0,41 \\
\hline Saúde do idoso & 3,73 & 0,55 & 4,44 & - & 1,11 & 0,63 \\
\hline Controle de doenças & 3,10 & 1,15 & 0,93 & - & 0,23 & 0,46 \\
\hline Vigilância sanitária & 2,25 & 0,68 & 2,69 & - & 1,68 & 0,87 \\
\hline Drogas & 2,70 & 0,91 & 1,35 & 1,44 & 0,72 & 0,78 \\
\hline Planos e seguros de saúde & 4,27 & - & 1,06 & - & 0,60 & 1,36 \\
\hline Outros temas & 2,30 & 1,13 & 1,42 & 1,07 & 1,13 & 0,78 \\
\hline
\end{tabular}

$\overline{\text { a Valor calculado dividindo-se a proporção de ações relativas a um tema realizadas por senadores de cada profissão, em relação ao total de ações realizadas relativas ao tema, pela proporção }}$ de senadores de cada profissão em relação ao total de senadores. Quanto mais próximo de 1, mais parecida é a intensidade da atuação por parte do grupo com a proporção com que ele se representa no plenário. O grau de prioridade ou de ausência de prioridade que o grupo considerado confere ao tema é dado pelo grau de afastamento do valor 1 , respectivamente para mais e para menos.

cativa apenas no tema "saúde reprodutiva", tanto em termos de parlamentares envolvidos, quanto de ações realizadas (tabelas 6-8).

Os parlamentares liberais e de direita foram responsáveis pelo maior número de ações (43\%), mas foram os de orientação socialista e trabalhista os que apresentaram participação mais positiva (22\%) (tabela 9). Os parlamentares dessa orientação apresentaram, na quase totalidade dos temas, uma participação elevada (indicadores maiores do que 1), tanto em relação ao número de senadores envolvidos quanto de ações realizadas. É de ressaltar que os senadores de orientação socialista e trabalhista não se envolveram com o tema "saúde do trabalhador".

Os parlamentares de orientação liberal e de direita clássica, ainda que tenham contribuído com a maioria das ações, envolveram-se, em proporção significativa, apenas com pouquíssimos temas, como, por exemplo, "saúde do trabalhador", "vigilância sanitária" e "drogas".

Os senadores centristas, que são $28 \%$ do plenário, realizaram apenas $20 \%$ das ações, envolvendo-se positi- vamente com poucos temas ("controle de doenças" e "vigilância sanitária").

Os social-democratas apresentaram uma participação proporcional $(14 \%$ das ações) à dimensão de sua bancada, envolvendo-se com apenas dois temas: "transplantes" e "planos e seguros de saúde" (tabelas 10 e 11).

\section{DISCUSSÃO}

O exame dos temas apresentou certos elementos em comum a todos. Em relação à análise da ação, destacaram- 
TABELA 5. Proporção das ações realizadas por senadores médicos na área de saúde pública, Brasil, 1995 e 1996

\begin{tabular}{lrrr}
\hline & & \multicolumn{2}{c}{ Médicos } \\
\cline { 3 - 4 } \multicolumn{1}{c}{ Temas } & Total & No. & $\%$ \\
\hline Políticas públicas & 198 & 37 & 19 \\
Regulamentação das profissões de saúde & 55 & 9 & 16 \\
Saúde reprodutiva & 33 & 7 & 21 \\
Alimentação e nutrição & 19 & 1 & 5 \\
Saúde da criança & 31 & 3 & 10 \\
Saúde do idoso & 20 & 5 & 25 \\
Controle de doenças & 48 & 10 & 21 \\
Saúde do trabalhador & 38 & 10 & 13 \\
Transplantes & 32 & 5 & 31 \\
Vigilância sanitária & 33 & 11 & 15 \\
Drogas & 61 & 6 & 18 \\
Planos e seguros de saúde & 21 & 12 & 29 \\
Outros temas & 78 & 121 & 18 \\
$\quad$ Total & 667 & & 18 \\
& & & \\
\hline
\end{tabular}

se a predominância da espécie discurso, cujo tema, em sua maioria, era de caráter regional e específico, respondendo a fatores conjunturais externos, notadamente notícias veiculadas pela imprensa regional e nacional; o caráter pontual da maioria das ações legislativas, abordando aspectos específicos, poucas vezes tratando de uma política do setor saúde, ou mesmo em relação aos temas considerados, em termos abrangentes e integrados; e a atividade fiscalizadora limitada, em que pese a constituição de algumas comissões de inquérito e especiais no período, com relativamente poucos requerimentos de informação e nenhuma atividade de acompanhamento da execução das recomendações do Legislativo (tabela 2).

Em termos individuais e partidários, supunha-se que a formação profissional, a orientação político-ideológica e, mesmo, as peculiaridades das regiões de origem do parlamentar constituíssem variáveis determinantes de uma priorização maior ou menor em matérias relativas à saúde pública, com reflexos na atuação do parlamentar. A situação difícil da saúde pública no Brasil também levou à suposição de que os parlamentares teriam investido substancialmente nas atividades de fiscalização e de que os projetos de lei apresentados teriam uma relação imediata com a necessidade de reformulação das políticas públicas do setor.

Contudo, a predominância de discursos, a influência dos meios de comunicação, a participação pontual e descontínua e, especialmente, a incipiente ação fiscalizadora do Legislativo, servem para indicar a necessidade de reformular a sistemática de trabalho, tanto no âmbito das comissões técnicas como, conseqüentemente, da assessoria técnica.

Em relação à elevada participação dos senadores das Regiões Norte e Nordeste (62\% das ações), é preciso lembrar que, no período estudado, ocorreram, nessas regiões, vários episódios relacionados ao setor de saúde (entre eles, óbitos por intoxicação em pacientes de serviços de hemodiálise, hipermortalidade de bebês em maternidades, epidemia de malária em cidades da região Amazônica) (18-20) que tiveram muita cobertura da imprensa e, conseqüentemente, foram objeto de

TABELA 6. Senadores envolvidos com temas de saúde pública e número de ações desenvolvidas segundo a região de origem, Brasil, 1995 e 1996

\begin{tabular}{|c|c|c|c|c|c|c|c|c|c|c|}
\hline \multirow[b]{2}{*}{ Tema } & \multicolumn{2}{|c|}{ Norte } & \multicolumn{2}{|c|}{ Nordeste } & \multicolumn{2}{|c|}{ Centro-Oeste } & \multicolumn{2}{|c|}{ Sudeste } & \multicolumn{2}{|c|}{ Sul } \\
\hline & No. & Ações & No. & Ações & No. & Ações & No. & Ações & No. & Ações \\
\hline Políticas públicas & 17 & 47 & 14 & 62 & 12 & 33 & 6 & 36 & 5 & 20 \\
\hline Regulamentação das profissões de saúde & 10 & 26 & 7 & 16 & 5 & 7 & 2 & 4 & 1 & 2 \\
\hline Saúde reprodutiva & 4 & 16 & 3 & 6 & 2 & 3 & 2 & 2 & 2 & 6 \\
\hline Alimentação e nutrição & 2 & 3 & 4 & 8 & 3 & 4 & 2 & 4 & - & - \\
\hline Saúde da criança & 9 & 15 & 8 & 9 & 2 & 2 & 2 & 3 & 1 & 2 \\
\hline Saúde do idoso & 3 & 4 & 5 & 6 & 1 & 4 & 2 & 5 & 1 & 1 \\
\hline Controle de doenças & 8 & 18 & 5 & 8 & 4 & 7 & 3 & 12 & 2 & 3 \\
\hline Saúde do trabalhador & 4 & 4 & 15 & 22 & 3 & 5 & 3 & 3 & 2 & 4 \\
\hline Transplantes & 3 & 6 & 7 & 16 & 3 & 4 & 6 & 6 & - & - \\
\hline Vigilância sanitária & 5 & 9 & 7 & 12 & 4 & 7 & 3 & 4 & 1 & 1 \\
\hline Drogas & 7 & 15 & 11 & 21 & 5 & 9 & 4 & 14 & 1 & 2 \\
\hline Planos e seguros de saúde & 7 & 11 & 1 & 5 & 2 & 2 & 2 & 2 & 1 & 1 \\
\hline Outros & 11 & 22 & 17 & 29 & 6 & 13 & 4 & 9 & 4 & 5 \\
\hline Total- $n(\%)$ & - & 196(29) & - & $220(33)$ & - & $100(15)$ & - & 104(16) & - & $47(7)$ \\
\hline
\end{tabular}

\footnotetext{
a Número de senadores.
} 
TABELA 7. Envolvimento dos senadores com temas de saúde pública conforme a região de origem, Brasil, 1995 e 1996

\begin{tabular}{lccccc}
\hline \multicolumn{1}{c}{ Temas } & Norte & Nordeste & Centro-Oeste & Sudeste & Sul \\
\hline Políticas públicas & 1,57 & 0,78 & 1,50 & 0,75 & 0,84 \\
Regulamentação das profissões & & & & & 0,36 \\
$\quad$ de saúde & 2,00 & 0,84 & 1,35 & 0,54 & 1,39 \\
Saúde reprodutiva & 1,54 & 0,69 & 1,04 & 1,04 & - \\
Alimentação e nutrição & 1,25 & 1,00 & 1,69 & 1,13 & 0,40 \\
Saúde da criança & 2,04 & 1,09 & 0,61 & 0,61 & 0,74 \\
Saúde do idoso & 1,25 & 1,25 & 0,56 & 1,13 & 0,82 \\
Controle de doenças & 1,82 & 0,68 & 1,23 & 0,92 & 0,67 \\
Saúde do trabalhador & 0,57 & 1,67 & 0,75 & 0,75 & - \\
Transplantes & 0,79 & 1,10 & 1,07 & 2,13 & 0,45 \\
Vigilância sanitária & 1,25 & 1,05 & 1,35 & 1,01 & 0,31 \\
Drogas & 1,25 & 1,18 & 1,21 & 0,97 & 0,69 \\
Planos e seguros de saúde & 2,69 & 0,23 & 1,04 & 1,04 & 0,85 \\
Outros temas & 1,31 & 1,22 & 0,96 & 0,64 & \\
\hline
\end{tabular}

a Valor calculado dividindo-se a proporção de senadores de cada região que se envolveram com o tema, em relação ao tota de senadores em cada região, pela proporção de senadores de cada região em relação ao total de senadores. Quanto mais próximo de 1, mais parecido é o envolvimento com o tema por parte do grupo com a proporção com que ele se representa no plenário. $\mathrm{O}$ grau de prioridade ou de ausência de prioridade que o grupo considerado confere ao tema é dado pelo grau de afastamento do valor 1 , respectivamente para mais e para menos.

TABELA 8. Intensidade da atuação dos senadores conforme a região de origem, Brasil, 1995 e $1996^{a}$

\begin{tabular}{lccccc}
\hline \multicolumn{1}{c}{ Temas } & Norte & Nordeste & Centro-Oeste & Sudeste & Sul \\
\hline Políticas públicas & 1,18 & 0,94 & 1,13 & 1,23 & 0,91 \\
Regulamentação das profissões & & & & & \\
$\quad$ de saúde & 2,36 & 0,87 & 0,86 & 0,49 & 0,32 \\
Saúde reprodutiva & 2,42 & 0,55 & 0,61 & 0,40 & 1,64 \\
Alimentação e nutrição & 0,80 & 1,26 & 1,42 & 1,42 & - \\
Saúde da criança & 2,42 & 0,87 & 0,43 & 0,65 & 0,58 \\
Saúde do idoso & 1,00 & 0,90 & 1,35 & 1,69 & 0,45 \\
Controle de doenças & 1,87 & 0,50 & 0,98 & 1,69 & 0,56 \\
Saúde do trabalhador & 0,40 & 1,74 & 0,53 & 0,89 & 0,95 \\
Transplantes & 0,93 & 1,53 & 0,85 & 1,26 & - \\
Vigilância sanitária & 1,36 & 1,09 & 1,43 & 0,82 & 0,27 \\
Drogas & 1,23 & 1,03 & 1,00 & 1,55 & 0,30 \\
Planos e seguros de saúde & 2,67 & 0,71 & 0,64 & 0,64 & 0,67 \\
Outros temas & 1,41 & 1,12 & 1,13 & 0,78 & 0,58 \\
\hline
\end{tabular}

a Valor calculado dividindo-se a proporção de ações relativas a um tema realizadas por senadores de cada região, em relação ao total de ações realizadas relativas ao tema, pela proporção de senadores de cada região em relação ao total de senadores. Quanto mais próximo de 1, mais parecida é a intensidade da atuação por parte do grupo com a proporção com que ele se representa no plenário. $\mathrm{O}$ grau de prioridade ou de ausência de prioridade que o grupo considerado confere ao tema é dado pelo grau de afastamento do valor 1, respectivamente para mais e para menos. nomes dos senadores, em combinação com os anos de 1995 e 1996, mostrou-se ineficaz para resgatar todas as proposições legislativas e discursos sobre saúde, pois ficou evidente que o universo de termos a ser pesquisado seria muito grande e ainda haveria o risco de não se ter identificado todos os que fossem pertinentes. Dessa forma, por exemplo, para a pesquisa do tema "saúde reprodutiva", deveriam ser utilizados, além desse, termos como planejamento familiar e anticoncepcional, controle de natalidade, controle populacional, esterilização, limitação da natalidade, limitação do número de filhos, método contraceptivo, pílula anticoncepcional, preservativo e vasectomia, sem, no entanto, esgotar o universo de possíveis indexações.

Isso explica a opção pela verificação de toda a lista de documentos, obtida utilizando-se, como indexador, o nome do senador, combinado com os anos estudados. Esse procedimento transformou um sistema automatizado de recuperação de informação em um sistema manual. O processo foi trabalhoso e lento, pois, para alguns parlamentares, obteve-se uma lista de até 500 documentos, que foram analisados um a um.

Também o período de 2 anos, muito reduzido para permitir o estabelecimento de séries temporais, limita a projeção de tendências para o médio e longo prazos. A ausência de estudos anteriores dificultou o estabelecimento de modelos mais operacionais.

As definições sobre as ações a serem consideradas, a época de filiação dos parlamentares, as profissões dos mesmos e a orientação ideológica dos partidos, dentre outros, exigiram o estabelecimento de critérios que, pelo caráter subjetivo de algumas determinações, estão abertos a críticas.

\section{CONCLUSÕES}

várias ações parlamentares, especialmente discursos.

\section{Críticas ao método}

Nossa maior dificuldade foi referente ao processo de coleta e processa- mento de dados, pois os bancos de dados disponíveis não permitiram a automatização do serviço. Especialmente, a indexação adotada pelos referidos bancos de dados dificultou o processo.

A tentativa de relacionar assuntos da área de saúde (grupos temáticos) aos
Com base nos resultados obtidos, evidenciou-se que a atuação do Senado Federal brasileiro, no período estudado, caracterizou-se por tratar as questões de saúde pública principalmente por meio de discursos em ple- 
TABELA 9. Ações na área de saúde pública conforme a orientação ideológica dos senadores, Brasil, 1995 e 1996

\begin{tabular}{|c|c|c|c|c|c|c|}
\hline Temas & Comunistas & $\begin{array}{l}\text { Socialistas e } \\
\text { trabalhistas }\end{array}$ & $\begin{array}{c}\text { Social- } \\
\text { democratas }\end{array}$ & Centro & $\begin{array}{c}\text { Liberais e } \\
\text { direita clássica }\end{array}$ & Total \\
\hline Políticas públicas & - & 58 & 26 & 47 & 67 & 198 \\
\hline Regulamentação das profissões de saúde & - & 16 & 8 & 10 & 21 & 55 \\
\hline Alimentação e nutrição & - & 5 & 1 & 4 & 9 & 19 \\
\hline Saúde da criança & - & 6 & 2 & 7 & 16 & 31 \\
\hline Saúde do idoso & - & 5 & 3 & 3 & 9 & 20 \\
\hline Transplantes & - & 10 & 13 & 3 & 6 & 32 \\
\hline Vigilância sanitária & - & 3 & - & 10 & 20 & 33 \\
\hline Drogas & - & 6 & 10 & 8 & 37 & 61 \\
\hline Planos e seguros de saúde & - & 4 & 8 & 2 & 7 & 21 \\
\hline Outros temas & 1 & 15 & 7 & 13 & 42 & 78 \\
\hline Total & 1 & 148 & 95 & 136 & 287 & 667 \\
\hline
\end{tabular}

TABELA 10. Envolvimento dos senadores com temas de saúde pública conforme a orientação ideológica, Brasil, 1995 e 1996 a

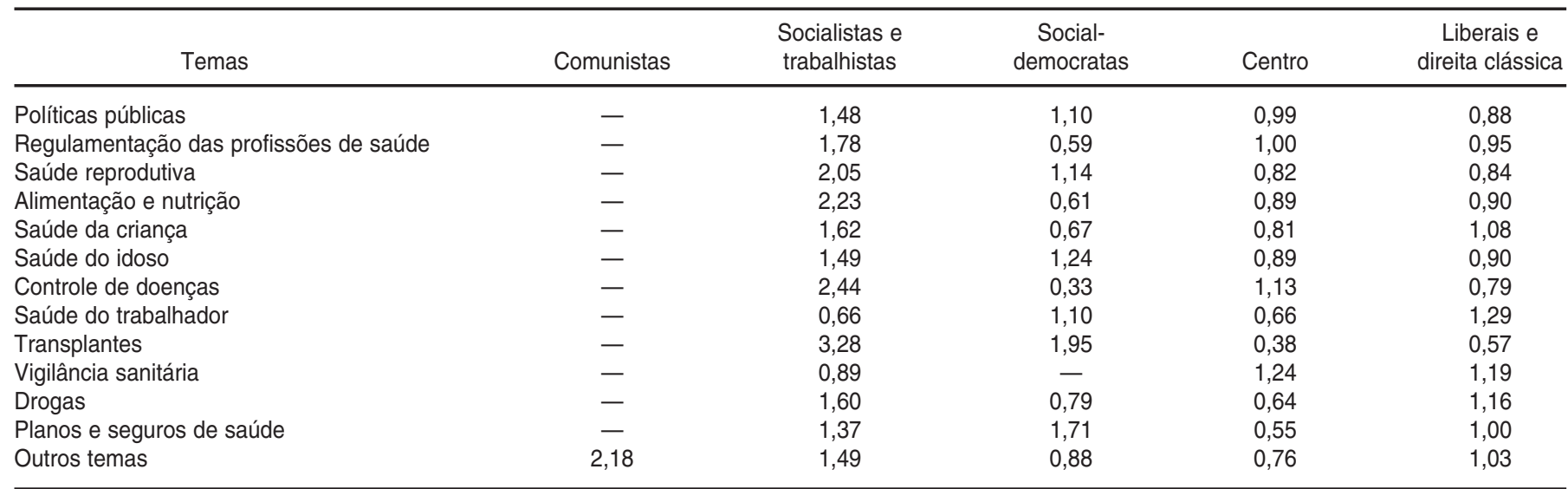

a Valor calculado dividindo-se a proporção de senadores de cada orientação ideológica que se envolveram com o tema, em relação ao total de senadores em cada orientação ideológica, pela proporção de senadores de cada orientação ideológica em relação ao total de senadores. Quanto mais próximo de 1, mais parecido é o envolvimento com o tema por parte do grupo com a proporção com que ele se representa no plenário. O grau de prioridade ou de ausência de prioridade que o grupo considerado confere ao tema é dado pelo grau de afastamento do valor 1 , respectivamente para mais e para menos.

nário e com razoável produção legislativa, mas praticamente nenhuma ação fiscalizadora.

No que se refere ao caráter pontual dos projetos de lei e à participação esporádica do legislativo na formulação e na fiscalização das políticas públicas de saúde, seria recomendável que as comissões técnicas da casa estabelecessem procedimentos operacionais capazes de aperfeiçoar as ações parlamentares nessa matéria, especialmente no que se refere às ações de acompanhamento e avaliação. Tal alteração impli- caria em mudanças na sistemática de trabalho das comissões e, conseqüentemente, da consultoria legislativa, privilegiando as atividades de acompanhamento e de avaliação, com maior integração institucional entre os órgãos do Executivo e os representantes do Legislativo.

Em relação ao perfil dos senadores, confirmou-se a influência da profissão, da orientação ideológica do partido e da região de origem dos mesmos no seu envolvimento com matérias de saúde pública. Os senadores médicos e membros de outras profissões do campo social, como professores e jornalistas, bem como os filiados a partidos de orientação socialista e trabalhista, foram os que mais se ocuparam das matérias de saúde pública no período estudado. Em relação à região de origem, a preponderância de senadores das Regiões Norte e Nordeste poderia ser relacionada tanto às condições de pobreza e menor desenvolvimento dos sistemas de saúde locais, quanto a fatores conjunturais no período, muito divulgados pela imprensa. 
TABELA 11. Intensidade da atuação dos senadores conforme a orientação ideológica, Brasil, 1995 e $1996^{a}$

\begin{tabular}{|c|c|c|c|c|c|}
\hline Temas & Comunistas & $\begin{array}{l}\text { Socialistas e } \\
\text { trabalhistas }\end{array}$ & $\begin{array}{c}\text { Social- } \\
\text { democratas }\end{array}$ & Centro & $\begin{array}{c}\text { Liberais e } \\
\text { direita clássica }\end{array}$ \\
\hline Políticas públicas & - & 2,62 & 0,97 & 0,84 & 0,73 \\
\hline Regulamentação das profissões de saúde & - & 2,60 & 1,07 & 0,65 & 0,83 \\
\hline Alimentação e nutrição & - & 2,35 & 0,38 & 0,75 & 1,03 \\
\hline Saúde da criança & - & 1,73 & 0,47 & 0,80 & 1,12 \\
\hline Saúde do idoso & - & 2,23 & 1,11 & 0,53 & 0,97 \\
\hline Transplantes & - & 2,79 & 3,00 & 0,33 & 0,40 \\
\hline Vigilância sanitária & - & 0,81 & - & 1,08 & 1,31 \\
\hline Drogas & - & 0,87 & 1,21 & 0,47 & 1,32 \\
\hline Planos e seguros de saúde & - & 1,70 & 2,82 & 0,34 & 0,72 \\
\hline Outros temas & 1,18 & 1,71 & 0,67 & 0,59 & 1,17 \\
\hline
\end{tabular}

a Valor calculado dividindo-se a proporção de ações relativas a um tema realizadas por senadores de cada orientação ideológica, em relação ao total de ações realizadas relativas ao tema, pela proporção de senadores de cada orientação em relação ao total de senadores. Quanto mais próximo de 1, mais parecida é a intensidade da atuação por parte do grupo com a proporção com que ele se representa no plenário. 0 grau de prioridade ou de ausência de prioridade que o grupo considerado confere ao tema é dado pelo grau de afastamento do valor 1 , respectivamente para mais e para menos.

\section{REFERÊNCIAS}

1. Fernandes M. Agonia macabra: as mortes na máquina de hemodiálise em Caruaru marcaram a maior calamidade na história recente da Medicina brasileira. Veja 1996;29(14):36-39.

2. Miranda R. Comissão Nacional de Bispos do Brasil exige explicação de Jatene para 'um dos maiores escândalos desse país'. O Globo 1996; 15 de abril:4.

3. Pompeu R, Augusto A. Hemodiálise: morre a 51aㅡ vítima: falta de controle da água em Caruaru provocou a maior tragédia involuntária de toda a história da humanidade. Jornal da Tarde 1996; 27 de maio:12A.

4. Alves ME. Relatório confirma horrores em asilo: documento feito pelo coordenador de vigilância sanitária do Estado será apresentado hoje na Assembléia Legislativa. O Globo 1996; 10 de junho:8.

5. Alves Filho F. Tragédia no depósito de velhos. Isto É 1996;1393(jun):108-115.

6. Pastore O. O triste outono. Veja 1996;29(24): 56-58.

7. Andrade P. Tragédia no berçário: superlotação em maternidade causa a morte de 51 bebês em 20 dias em Fortaleza. Isto É 1996; 1417(nov):26.

8. Grillo C. Dez bebês morrem em 15 dias em hospital de Niterói: índice de mortes atingiu
$12,5 \%$, quando o aceitável para a OMS é $6 \%$. Folha de São Paulo 1996; 7 de novembro:3.

9. Magno B, Varella J. Morre bebê ianomâmi: preocupado, o Governador de Rondônia visita o hospital e admite que só soube do caso quando 32 recém-nascidos já tinham morrido. Correio Braziliense 1996; 31 de outubro:8.

10. Melazo F, Botão A. Infecção se alastra nos Hospitais: pesquisa feita pelo próprio Ministério da Saúde mostra que os bebês de UTI neonatais são os mais expostos. Correio Braziliense 1996; 27 de outubro:17.

11. Brasil, Congresso, Senado Federal. Senadores: dados biográficos: qüinquagésima legislatura 1995-1999. Brasília: Senado Federal, Subsecretaria de Arquivo; 1995

12. A cabeça do Congresso: quem é quem na revisão constitucional. São Paulo: Oboré; 1993.

13. Uma pesquisa sobre os 100 parlamentares mais influentes no Poder Legislativo. Brasília: DIAP; 1997. [Série Os Cabeças do Congresso Nacional 4].

14. Brasil. Relatório da Presidência do Senado Federal. Brasília: Senado Federal; 1995.

15. Brasil. Relatório da Presidência do Senado Federal. Brasília: Senado Federal; 1996.

16. Brasil, Ministério da Saúde. Saúde no Brasil. Brasília: Ministério da Saúde; 1997.
17. Instituto Brasileiro de Geografia e Estatística (IBGE), Departamento de População e Indicadores Sociais. Síntese de indicadores sociais 1998. Rio de Janeiro: IBGE; 1999. [Estudos e pesquisas, informação demográfica e socioeconômica; 1].

18. Farias $\mathrm{O}$. Malária poderá atingir 1 milhão na Amazônia. Jornal do Brasil 1994; 15 de dezembro:17.

19. Gutkoski C. Malária infecta 80 por dia no Maranhão: número de casos aumentou $74 \%$ em comparação com o ano anterior; falta verba para combate. Folha de São Paulo 1995; 28 de fevereiro:3.

20. Soares A. Malária que mata em 6 dias ataca 10 mil pessoas no Pará: doença avança e governo diz não ter controle sobre epidemia. Jornal do Brasil 1995; 17 de maio:7.

Manuscrito recebido em 24 de agosto de 1998. Aceito em versão revisada em 11 de junho de 1999. 
ABSTRACT The objective of this study was to identify and describe the actions of Brazilian senators in the field of public health in 1995 and 1996. We also sought to determine if profession, regional background, or political party influenced the senators' actions. The actions were divided into three types: legislative (proposal and review of bills and petitions); supervisory (information requests to the executive branch and the establishment of inquiry committees and other special committees); and parliamentary (speeches). The data were collected from two databases maintained by the Senate, namely MATE and DISC. Of the 89 senators who were in office during the study period, 76 were involved with public health issues. Of the total of 667 actions studied, there was a predominance of speeches (43\% of all actions), most of them responding to news reported by regional or national media. Supervisory activities were limited (5\% of all actions were information requests). The subjects dealt with most frequently were health policies $(30 \%)$, drugs $(9 \%)$, regulation of health professions $(8 \%)$, disease control (7\%), and worker health (6\%). Concerning the professions of the senators, the most frequent categories were physicians, teachers, and journalists. The senators representing the North and Northeast regions performed $62 \%$ of the actions and were involved with almost all the health subjects. Although $43 \%$ of the actions were carried out by liberal and right-wing senators, the senators from socialist and labor parties had a stronger proportional participation (both in terms of senators involved and actions performed). It is interesting to note that socialist and labor senators showed minimal involvement in the issue of worker health. The predominance of speeches as a prevalent type of action, the limited and disjointed scope of legislative actions, and, especially, the poor monitoring and control show the need for deep changes in the work process of the Senate's technical committees and, therefore, of the Senate's technical support unit. 